\title{
Experimental investigation on breakdown characteristics of sand, bentonite and their mixes
}

\begin{abstract}
Experimental work conducted on the impact of soil and bentonite on transient performance of grounding systems has been reported. Three soil samples were tested after classifying them under their texture and grain size. Resistivity and permittivity were found to decrease with frequency, in all samples. The resistivity of sand-bentonite mixed at 1:1 ratio by volume, was decreased by $86 \%$ compared to that of sand whereas the breakdown voltage was decreased by $20.5 \%$ for positive and $30 \%$ for negative impulses, compared with the same parameters of sand. Air-voids may be playing an important role in the breakdown process.
\end{abstract}

Keyword: Soil structure; Soil frequency dependence; Soil breakdown voltage; Bentonite clay 